\title{
Wedge Shock and Nozzle Exhaust Plume Interaction in a Supersonic Jet Flow
}

\author{
Raymond Castner ${ }^{1}$, Khairul Zaman ${ }^{2}$, Amy Fagan ${ }^{3}$, and Christopher Heath ${ }^{4}$. \\ NASA Glenn Research Center, Cleveland, Ohio, 44135, USA
}

Fundamental research for sonic boom reduction is needed to quantify the interaction of shock waves generated from the aircraft wing or tail surfaces with the nozzle exhaust plume. Aft body shock waves that interact with the exhaust plume contribute to the near-field pressure signature of a vehicle. The plume and shock interaction was studied using computational fluid dynamics and compared with experimental data from a coaxial convergent-divergent nozzle flow in an open jet facility. A simple diamond-shaped wedge was used to generate the shock in the outer flow to study its impact on the inner jet flow. Results show that the compression from the wedge deflects the nozzle plume and shocks form on the opposite plume boundary. The sonic boom pressure signature of the nozzle exhaust plume was modified by the presence of the wedge. Both the experimental results and computational predictions show changes in plume deflection.

\section{Nomenclature}

NPR $=$ Nozzle pressure ratio $=P_{t} / P_{\infty}$

$\mathrm{P}=$ Local static pressure, psia

$\mathrm{P}_{\mathrm{o}}=$ Total pressure in nozzle plenum, psia

$\mathrm{P}_{\infty}=$ Free-stream static pressure, $\mathrm{psia}$

$\Delta \mathrm{P}=\mathrm{P}-\mathrm{P}_{\infty}$

$\mathrm{T}_{0}=$ Nozzle total temperature, $\mathrm{R}$

$\mathrm{T}_{\infty}=$ Free-stream total temperature, $\mathrm{R}$

$\mathrm{x}=$ Distance along abscissa of pressure signature, in

$\mathrm{y}=$ Horizontal distance from nozzle centerline, in

$\mathrm{z}=$ Vertical distance from nozzle centerline, in

\section{Introduction}

$\mathrm{T}$ he reduction of sonic boom overpressures of supersonic aircraft may enable high speed travel over populated areas. The impact of the sonic boom on populated areas is so large that the FAA has prohibited supersonic flight over land by civil aircraft in the United States. Most supersonic aircraft produce an N-wave pressure signature on the ground; a rise in pressure from the bow shock of the vehicle followed by an expansion to a negative pressure and then the return to atmospheric pressure. The bow and tail shocks create the "double boom" often heard on the ground. The aircraft pressure signature near the vehicle has multiple shocks and expansions that attenuate and coalesce to the $\mathrm{N}$-wave form on the ground.

Recent studies to develop aircraft with acceptable sonic boom noise include programs such as the Quiet Spike $^{1}$ and the Shaped Sonic Boom Demonstrator (SSBD) ${ }^{2}$ that achieved reduced intensity of the forward portion of the pressure signature. Research was also done to reduce the contribution from aft components including the nozzle exhaust. One example was the work of Putnam ${ }^{3}$, who performed an experimental study of exhaust nozzles and the effects of the exhaust plume. Tests were performed in a 4-foot by 4-foot supersonic wind tunnel with pressure measurements taken one diameter away from the nozzle. Study of exhaust nozzle plume effect on sonic boom has progressed from analysis and testing of an isolated nozzle ${ }^{4,5}$, to slot nozzles ${ }^{6}$ and engine-wing-body models $\mathrm{s}^{7,8}$. These studies demonstrated how the nozzle lip shock from an under-expanded nozzle plume could suppress the nozzle boat-tail expansion and reduce the trailing shock. One previous study has examined the exhaust nozzle

\footnotetext{
${ }^{1}$ Aerospace Engineer, Inlet and Nozzle Branch, 21000 Brookpark Road, and AIAA Associate Fellow.

${ }^{2}$ Aerospace Engineer, Inlet and Nozzle Branch, 21000 Brookpark Road, and AIAA Associate Fellow.

${ }^{3}$ Aerospace Engineer, Optical Instrumentation Branch, 21000 Brookpark Road, and AIAA Associate Fellow.

${ }^{4}$ Aerospace Engineer, Multidisciplinary Design Analysis Optimization Branch, 21000 Brookpark Rd.
} 
plume interaction with shocks generated by the wing and tail, which may affect the plume shape and the sonic boom signature ${ }^{9}$.

The subject of this report is the study of a simplified exhaust nozzle plume interaction with a tail shock, generated by a simple wedge of diamond-shaped cross section. The primary objective is to provide a baseline analysis of a generic nozzle and wedge configuration, and demonstrate the effect of the wedge shock waves on the nozzle exhaust plume. A secondary objective was to evaluate the ability of existing CFD tools to capture the plume and shock interaction effects. The work was performed in a fundamental flow physics lab at the NASA Glenn Research Center (GRC) on a small scale and at a relatively low cost. In this manner, data for a nozzle plume and shock interaction was collected. The WIND-US, FUN3D, and Cart3D computational fluid dynamic (CFD) codes were used for analysis and comparison to experiment. The Mach number contours and pressure profiles are presented.

\section{CFD Analysis}

\section{A. Geometry}

The experiment was run on a coaxial nozzle designed to provide an inner supersonic nozzle plume, immersed in an outer supersonic free jet. The nominal design Mach number of the inner nozzle was 1.6 with the throat ( $\mathrm{d}=0.50 \mathrm{in}$.) located 0.665 in. upstream of the exit (Fig. 1). The coordinate system is also shown in Fig. 1. Note that the origin of the stream wise $x$-coordinate is at the entrance to the nozzle system, 7.5 inches upstream of the exit. The origin of the transverse (z) and lateral (y) coordinates are at the nozzle centerline. The nominal design Mach number of the outer passage was Mach 1.6 with the throat 1.651 in. upstream of the exit. The outer nozzle possessed an exit diameter of 2 inches, and the inner nozzle had an exit diameter of 0.553 inch $(0.040$ inch lip thickness). The shock generator was a diamond-shaped wedge with a 0.20 inch chord and 0.08 inch thickness. It was 4 inches long and spanned the lower portion of the outer free jet. The leading edge of the wedge was located at $\mathrm{z}=-0.95$ inch below the centerline and at an axial location of $\mathrm{x}=8.5 \mathrm{in}$., or 1 inch downstream of the nozzle exit.

\section{B. CFD Codes}

\section{Wind-US}

The first CFD code used was Wind-US version 2.0, which is a general purpose fluid flow solver ${ }^{10}$. The established capability of Wind-US was used to compute nozzle plumes with viscous and turbulence effects. The code supports the solution of the Euler and Navier-Stokes equations of fluid mechanics, along with supporting equation sets governing turbulent flows. Wind-US was used with the modified second order Roe upwind scheme for stretched grids, implicit time stepping with a CFL number of 1.0, and the Menter Shear Stress Transport (SST) turbulence model.

\section{2. $\operatorname{Cart} 3 D$}

Cart3 $\mathrm{D}^{11,12}$ is a high-fidelity analysis package for conceptual and preliminary aerodynamic design that provides solution to the Euler equations. It allows users to perform automated CFD analysis on complex geometry. Geometry for Cart3D is represented by surface triangulations. These may be generated from within a ComputerAided Design (CAD) system, from legacy surface triangulations or from diagonalized (diagonal added to each quadrilateral face) structured surface grids. Cart3D uses an embedded multilevel Cartesian mesh to discretize the space surrounding the geometry and determines the surface geometry out of the set of "cut-cells" which intersect the surface triangulation. The flow solver is parallelized via Open Multi-Processing (OPENMP) and can take advantage of multi-core and multi-CPU hardware. Solutions were obtained using the adjoint-based mesh adaptation module ${ }^{13-}$ ${ }^{15}$. This module uses adjoint-weighted residual error-estimates to drive mesh adaptation. Once a user specifies the output function of interest, such as lift, drag, or off-body pressures along a line with a corresponding error tolerance; the module automatically refines the mesh to drive the remaining numerical errors below the requested tolerance. This module combined with domain rotation to nearly align the mesh with the Mach angle has been validated for sonic boom prediction by Wintzer ${ }^{16}$ and others with and without adaptation ${ }^{17-20}$. The adaptation module allows greatly reduced mesh generation and analysis time and offers effective use of computational resources for an accurate solution. 


\section{FUN3D}

FUN3D ${ }^{21-25}$ is a finite-volume Navier-Stokes solver in which the flow variables are stored at the vertices or nodes of the mesh. FUN3D solves the equations on mixed element grids, including tetrahedra, pyramids, prisms, and hexahedra and also has a two-dimensional path for triangular/quadrilateral grids. At interfaces delimiting neighboring control volumes, the inviscid fluxes are computed using an approximate Riemann solver based on the values on either side of the interface. Several convective flux schemes are available in FUN3D. The most common scheme for subsonic and transonic flows is Roe's flux difference splitting ${ }^{26}$. For second-order accuracy, interface values are obtained by extrapolation of the control volume centroidal values, based on gradients computed at the mesh vertices using an un-weighted least-squares technique. Several reconstruction limiters are available in FUN3D. The most commonly used is that of Venkatakrishnan ${ }^{24}$.

The solution at each time-step is updated with a backwards Euler time-integration scheme. At each time step, the linear system of equations is approximately solved with either a multi-point implicit procedure or an implicit-line relaxation scheme ${ }^{27}$. Local time-step scaling is employed to accelerate convergence to steady state. For turbulent flows, several models are available within FUN3D. In the current study, only the loosely coupled SpalartAllmaras (SA) model $^{28}$ was used for FUN3D.

\section{Domain and Flow Conditions}

\section{Wind-US}

The computational domain was an axisymmetric structured grid which consisted of 6 zones, and 213,100 grid points (Fig. 2). The domain extended 7 nozzle diameters downstream of the nozzle exit. Multiblock wallpacked grids were generated for use on parallel processor systems. Viscous wall boundaries were used for all nozzle surfaces. Convergence was monitored with nozzle mass flow. Flow conditions are outlined in Table 1. A calculation was completed for the case with no wedge, as this was an axisymmetric solution allowing simplified grid generation. A structured grid solution was not modeled for the three-dimensional coaxial nozzle and wedge geometry; FUN3D was instead used to solve an unstructured grid model.

\section{2. $\operatorname{Cart3D}$}

Surface geometry for Cart3D was generated for the coaxial nozzle, as shown in Fig. 3. The nozzle flow field was simulated with a pressure boundary at the nozzle plenum, and Cart3D computations of the nozzle plume were obtained at flow conditions outlined in Table 1. A conical fairing was used upstream of the plenum to create a closed geometry, and the computational domain extended 10 body lengths in all directions. Line sensors downstream of the nozzle exit were used to drive the mesh adaptation. One line sensor was on the centerline at $\mathrm{z}=0$ in. and another was one diameter above the centerline at $\mathrm{z}=0.553 \mathrm{in}$. Seven levels of grid adaptation were completed and the final mesh contained 22 million grid points. A calculation was completed with the coaxial nozzle and wedge; a case without the wedge would have dramatically changed the automated mesh adaptation, and was not performed for comparison.

\section{FUN3D}

The computational domain was an unstructured tetrahedral grid which consisted of 13.1 Million cells (Fig. 4). The domain extended 14 inches downstream of the nozzle exit. The wedge was placed at 1.0 inch downstream of the nozzle exit and 0.95 inches below the nozzle centerline. A plume baffle strategy was used downstream of the nozzle lip, both outer and inner, to generate a dense region of unstructured grid elements in the plume region, as seen in Fig. 4e. Viscous wall boundaries were used for all nozzle surfaces. Convergence was monitored using maximum residuals. Flow conditions are outlined in Table 1. Simulations were completed both with and without the wedge.

\section{Experiment}

\section{A. Test Setup}

The co-annular nozzle, as described in section IIA, was installed in a free jet facility. The CW-17 facility is used to conduct experiments to develop fundamental understanding of jet flows. CW-17 consists of a plenum chamber and a nozzle, where the 30-inch diameter plenum is supplied with a maximum of 70-psig high pressure air. Using adaptors, various nozzles can be mounted off the plenum chamber. The nozzle exhausts into the ambient air 
conditions of the test chamber. Test conditions are outlined in Table 1, but the experimental nozzle pressure ratio (NPR) was slightly higher at NPR=4.64.

Pitot tubes mounted on an actuator system were used to survey the flow field downstream of the nozzle exit. Conventional schlieren and focused schlieren systems were used for flow visualization.

\section{B. Model}

The experiment was run with the same configuration as described in section IIA, a co-annular nozzle designed to provide an inner supersonic nozzle plume immersed in an outer supersonic free jet. A diamond-shaped wedge with a 0.20 inch chord and a 0.08 inch thickness was used as a shock generator. It was 2 inches long, spanned the lower portion of the outer free jet, the leading edge was located at $\mathrm{z}=-0.95$ inch below centerline and at an axial location of $x=8.5$ in. A photo is provided in Fig. 5. The same wedge geometry was tested in a second location at $\mathrm{z}=-0.61 \mathrm{in}$. and $\mathrm{x}=8.0$ in.

\section{Instrumentation}

Shadowgraph data were obtained. Experiments were completed with a total pressure probe to determine nozzle exit Mach number, and a static pressure probe (Pinckney probe $^{29}$ ) to determine near-field static pressure profiles $(\Delta \mathrm{P} / \mathrm{P})$ downstream of the nozzle.

\section{Results and Discussion}

\section{A. Nozzle Plume with No Wedge}

\section{1) No Wedge Shadowgraph Images}

A shadowgraph image for the co-annular nozzle with no wedge shock generator (wedge) was collected. The shadowgraph image displays the interaction of the lip shock from both the inner nozzle and outer free jet, which caused a Mach disk and shock diamonds within the free jet flow. The inner nozzle flow is distinguishable from the outer free jet flow and the shear layer is clearly visible (Fig. 6a). Static pressure data $(\Delta \mathrm{P} / \mathrm{P})$ were collected at one nozzle diameter above the centerline, at $\mathrm{z}=0.553$ in., allowing analysis of the shock waves within the outer free jet flow field. Later in this report, data will be presented with a wedge placed below the inner nozzle simulating the shock wave generated by an aircraft wing or tail. The location at $\mathrm{z}=0.553 \mathrm{in}$. was used to assess the ability of the CFD codes to capture the interaction of the wedge shock after it had passed through the inner nozzle plume. The static pressure profile was characterized by a rise in pressure at $\mathrm{x}=8 \mathrm{in} ., 10.5 \mathrm{in}$., and $11.25 \mathrm{in}$., caused by the internal shock diamond structure, as shown in Fig. $6 \mathrm{~b}$. Total pressure was also measured at $\mathrm{z}=0.553$ in. and the variation of total pressure within the shock diamond structure is shown in Fig. 6c. Uncertainty of the pressure measurements was $+/-0.15 \%$, well within the symbols used to plot the results.

The static pressure and total pressure measurements were repeated for the nozzle centerline, $\mathrm{z}=0 \mathrm{in}$., and show the strong shock and decay at $\mathrm{x}=8 \mathrm{in}$. where the flow from the inner nozzle formed a Mach disk (Fig. $6 \mathrm{~d}$ and Fig. 6e). Finally, the total pressure across the exit of the nozzle was collected at a location of $x=7.540$ in., or 0.040 in. downstream of the lip. The exit flow profiles of the inner nozzle and the outer free jet are uniform, with some pressure loss exhibited in the core flow nozzle, see Fig. 6 f.

\section{2) No Wedge - Wind-US}

Mach number contours for the co-annular nozzle with no wedge were computed with Wind-US. Results were similar to the experimental shadowgraph images. The contours show the formation of the shock diamonds downstream of both the inner nozzle and the outer free jet flow. For the inner nozzle, a strong shock diamond is generated between $\mathrm{x}=7.5$ in. and 9.0 in., and a small Mach disk forms on the centerline. Behind the small Mach disk, a wake is formed which persists through the solution, see Fig. 7a. This wake can also be seen in the experimental shadowgraph. The shear layer between the inner nozzle and the outer free jet is also clearly resolved in the Wind-US solution.

The static pressure profile was computed at the same $\mathrm{z}=0.553$ in. location as in the experiment. The WindUS solution captures the rise in pressure at $\mathrm{x}=8$ in., 10.5 in. and 11.25 in., caused by the internal shock diamond structure, see Fig. $7 \mathrm{~b}$. The maximum deviation from the experimental data in $\Delta \mathrm{P} / \mathrm{P}=0.24$, which occurred at $\mathrm{x}=8.5$ 
in. The total pressure trends were also captured within the shock diamond structure, but both peaks and troughs were lower in magnitude than the experimental data (Fig. $7 \mathrm{c}$ ). The maximum deviation in $\mathrm{P}_{\mathrm{t}} / \mathrm{P}_{\mathrm{o}}=0.08$, which occurred at $\mathrm{x}=8.5 \mathrm{in}$.

Both static pressure and total pressure data were computed at the coaxial nozzle centerline location, $\mathrm{z}=0$ in. The static pressure profile (Fig. 7d) captured the strong shock and decay at $\mathrm{x}=8$ in. due to the Mach disk downstream of the inner nozzle. It is typical for experimental data to miss the sharp peak at $\mathrm{x}=8 \mathrm{in}$., as the probe did not stop at the exact location where the maximum value occurred. At $x=9.75$ in., the maximum difference between the CFD and the experiment was $\Delta \mathrm{P} / \mathrm{P}=0.2$. The total pressure profile (Fig. 7e) shows a large difference in $\mathrm{P}_{\mathrm{t}} / \mathrm{P}_{\mathrm{o}}=0.15$ at the location of $x=9.5$ in., a location behind the strong barrel shock on the centerline. In this case the CFD under-predicts the expansion due to the numerical dissipation inherent in Reynolds-averaged Navier-Stokes calculations. Following the strong shock, the total pressure profile never fully recovered. Finally, the uniform total pressure across the exit of the coaxial nozzle was computed at the same location of $x=7.540$ in. as in the experiment, as shown in Fig. 7f. The total pressure loss noted for the inner nozzle flow was also captured by the simulation.

\section{3) No Wedge - FUN3D}

Mach number contours for the co-annular nozzle with no wedge were computed with FUN3D. Results were similar to the experimental shadowgraph images and the Wind-US results. However, the Mach contours do not appear as sharp as in the Wind-US solution. Shock diamonds between $\mathrm{x}=8 \mathrm{in}$. and $10 \mathrm{in}$. are easily traced, but those between $x=10$ in. and 12 in. are more difficult to discern. At $x=8$ in., the Mach disk is evident, but there is no wake downstream of the disk. Also, the shear layer between the inner nozzle and outer free jet is evident, but loses some clarity downstream of $x=11$ in., see Fig. 8 a.

Static pressure was again computed for the location one diameter above the inner nozzle centerline, $\mathrm{z}=0.553$ in. FUN3D captured the trends in the static pressure profile, but missed the rise in pressure at $\mathrm{x}=8$ in. A rise in pressure was captured at $\mathrm{x}=10.5$ in. and 11.25 in. due to the internal shock diamond structure, although it is difficult to see the shock wave in the Mach contours at $x=11.25$ in. (Fig. 8b). For comparisons, both the Wind-US and FUN3D results are plotted in Fig. 8. Total pressure was also computed at $\mathrm{z}=0.553$ in., and the peaks and troughs were lower in magnitude than the experimental data, see Fig. 8c. Differences between the experimental data at $x=0.553$ in. and the FUN3D results at the same location were similar to previous differences with Wind-US.

Static pressure for the nozzle centerline, $\mathrm{z}=0$ in. exhibited similar results to the Wind-US solution, see Fig. 8d. However, the total pressure profile (Fig. 8e) again shows a large difference in $\mathrm{P}_{\mathrm{t}} / \mathrm{P}_{\mathrm{o}}=0.2$ at the location of $\mathrm{x}=9.5$ in. The total pressure was greater than in the Wind-US solution, and never fully recovered following the strong centerline barrel shock. Finally, the total pressure across nozzle exit (Fig. 8f) was similar to the Wind-US solution.

\section{B. Nozzle With Wedge}

\section{1) Shadowgraph Images, Wedge at $x=8.5 \mathrm{in}$. and $z=-0.95 \mathrm{in}$.}

A shadowgraph image for the effect of the wedge shock generator (wedge) was collected with the wedge installed downstream of the outer free jet exit plane at $x=8.5 \mathrm{in}$. and $\mathrm{z}=-0.95 \mathrm{in}$. The shadowgraph image displays the interaction of the lip shock from both the inner nozzle and outer free jet, which caused a Mach disk and shock diamonds within the free jet flow. The inner nozzle flow is distinguishable from the outer free jet flow and the shear layer is clearly visible. The shock wave generated from the leading edge of the wedge is called the leading shock, and the shock wave generated from the trailing edge of the wedge is the trailing shock (Fig. 9a). For the static pressure profile one nozzle diameter above the centerline $(\mathrm{z}=0.553 \mathrm{in}$.), the leading shock was observed at $\mathrm{x}=10.0$ in. and the trailing shock was observed at $\mathrm{x}=11 \mathrm{in}$. (Fig. 9b). This measurement location of $\mathrm{z}=0.553$ in. was on the top side of the inner nozzle plume, and provided an indication of how the leading and trailing shock waves from the wedge were affected by the inner nozzle plume. The leading and trailing shocks were also observed in the total pressure profile (Fig. 9c) at $\mathrm{x}=10$ in. and $\mathrm{x}=11$ in.

For the centerline data taken at $\mathrm{z}=0$ in, comparisons can be made to the results with no wedge present (Fig. $6 \mathrm{~d}$ ), at $\mathrm{x}=9.75$ in. the maximum $\Delta \mathrm{P} / \mathrm{P}$ was 0.6 , and was reduced to 0.1 by the presence of the leading shock, see Fig. $9 \mathrm{~d}$. Similarly, at $\mathrm{x}=10.75 \mathrm{in}$. the maximum $\Delta \mathrm{P} / \mathrm{P}$ was 0.55 , and was reduced to 0.5 by the influence of the trailing shock. Total pressure measurements at $x=9.75$ in. and $x=10.75$ in. were higher than the case with no wedge, see Fig. 9 e.

Total pressure surveys were conducted downstream of the nozzle plume and wedge shock interaction, at an axial location of 9.5 inches, or 2 inches downstream of the nozzle exit. The survey was conducted in the vertical direction from $\mathrm{z}=-1.5$ in. to $\mathrm{z}=1.5$ in. The total pressure data was not symmetric about the centerline ( $\mathrm{z}=0$ in.), indicating that the plume was deflected upward by the wedge (Fig. 9f), consistent with previous studies ${ }^{9}$. The static 
pressure was also surveyed downstream of the nozzle plume and wedge interaction, at the same location as the total pressure. This vertical profile was also non-symmetric (Fig. 9g) and shows that the nozzle plume was deflected upward by the wedge at this location.

2) FUN3D, Wedge at $x=8.5$ in. and $z=-0.95$ in.

Mach number contours for the coaxial nozzle and wedge simulation were computed using FUN3D. Fig. 10a shows both the leading and trailing shocks from the wedge as they propagate upward through the inner nozzle plume. Again, static pressure was computed above the inner nozzle plume at $\mathrm{z}=0.553$ in. When compared to the experimental data, FUN3D captured the static pressure profile throughout the coaxial nozzle flow field at this measurement location, with a maximum deviation in $\Delta \mathrm{P} / \mathrm{P}=0.15$ downstream of $\mathrm{x}=11$ in. The leading and trailing shocks are evident in Fig. $10 \mathrm{~b}$ at $\mathrm{x}=10$ in. and $\mathrm{x}=11$ in. The total pressure (Fig. 10c) was also computed at this location, with only minor deviations at locations greater than $x=11$ in. (maximum deviation in $P_{t} / P_{o}=0.12$ ), downstream of the trailing shock. Fig. 11d and Fig. 11e show both the static pressure and total pressure on the nozzle centerline, where the FUN3D results were consistent with the experimental measurements, with exception that changes in total pressure were under-predicted as discussed previously.

Total pressure was computed downstream of the nozzle plume and wedge shock interaction, at an axial location of 9.5 inches, or 2 inches downstream of the nozzle exit. The data was computed in the vertical direction from $\mathrm{z}=-1.0$ in. to $\mathrm{z}=1.0 \mathrm{in}$, and includes the supersonic flow only. The total pressure data was not symmetric about the centerline ( $\mathrm{z}=0$ in.), indicating that the plume was deflected upward by the wedge (Fig. 10f), and was consistent with the experiment. Finally, the static pressure was also computed downstream of the nozzle plume and wedge interaction, at the same location as the total pressure. This vertical profile was also non-symmetric (Fig. 10g) and shows that the nozzle plume was deflected upward by the wedge flow at this location, as in the experiment.

\section{3) Wedge Shock Cart3D CFD, Wedge at $x=8.5$ in. and $z=-0.95$ in.}

Mach number contours for the coaxial nozzle and wedge simulation were computed using Cart3D. Fig. 11a shows both the leading and trailing shocks from the wedge as they propagate upward through the inner nozzle plume. Again, static pressure was computed above the inner nozzle plume at $\mathrm{z}=0.553$ in. When compared to the experimental data, Cart3D captured the static pressure profile including the leading shock at $\mathrm{x}=10$ in. The trailing edge shock was at $\mathrm{x}=11.1$ in. instead of $\mathrm{x}=11 \mathrm{in}$. as in the experimental data (Fig. 11b). For comparison, both the FUN3D and Cart3D results are plotted in Fig. 11. The maximum deviation from experimental data in $\Delta \mathrm{P} / \mathrm{P}=0.64$ at $\mathrm{x}=11$ in. Total pressure (Fig. 11c) also shows some deviation from the experimental data at the trailing edge shock location, with a maximum deviation in $\mathrm{P}_{\mathrm{t}} / \mathrm{P}_{\mathrm{o}}=0.12$ at $\mathrm{x}=11$ in.

Static Pressure computations along the centerline show a different shock location at $\mathrm{x}=9.5 \mathrm{in}$. (Fig. 11d) and a difference between the CFD and the experimental value of $\Delta \mathrm{P} / \mathrm{P}=0.89$. The total pressure (Fig. 11e) was also computed on centerline, with a maximum deviation in $\mathrm{P}_{\mathrm{t}} / \mathrm{P}_{\mathrm{o}}=0.2$ at $\mathrm{x}=9.5$ in.

Static pressure was computed downstream of the nozzle plume and wedge shock interaction, at an axial location of 9.5 inches, or 2 inches downstream of the nozzle exit. The data was computed in the vertical direction from $\mathrm{z}=-1.0 \mathrm{in}$. to $\mathrm{z}=1.0 \mathrm{in}$, and includes the supersonic flow only. The total pressure data was not symmetric about the centerline $(\mathrm{z}=0$ in.), indicating that the plume was deflected upward by the wedge, and was consistent with the experiment, see Fig. 11f. No organized correlation was noted in the static pressure survey at the same location (Fig.11g). This lack of agreement is likely attributed to the inviscid solution generated by Cart3D, which did not properly capture the viscous shear layer between the inner nozzle plume and outer free jet plume at this axial location.

\section{4) Wedge Shock Shadowgraph Images, Wedge at $x=8.0 \mathrm{in}$. and $z=-0.61 \mathrm{in}$.}

A shadowgraph image for the effect of the wedge was collected with the wedge installed downstream of the outer free jet exit plane at $x=8.0$ in. and $z=-0.61$ in. This location provided an alternate location for the wedge and inner nozzle plume investigation. The shadowgraph image displays the interaction of the lip shock from both the inner nozzle and outer free jet, which caused a Mach disk and shock diamonds within the free jet flow. The inner nozzle flow is distinguishable from the outer nozzle flow and the shear layer is clearly visible. The wedge creates both a leading and trailing shock, as seen in Fig. 12a. For the static pressure profile one nozzle diameter above the centerline $(\mathrm{z}=0.553)$, the leading shock was observed at $\mathrm{x}=9.0 \mathrm{in}$. and the trailing shock was observed at $\mathrm{x}=10.75 \mathrm{in}$. (Fig. 12b). The leading and trailing shock were also observed in the total pressure profile (Fig. 12c) at $\mathrm{x}=9$ in. and $\mathrm{x}=10.75$ in. 
Centerline data (Fig. 12d and Fig. 12e), taken at $\mathrm{z}=0$ in., exhibits the strong shock and decay at $\mathrm{x}=8$ in. where the inner nozzle plume forms a Mach disk. The leading and trailing shocks from the wedge can be seen at $\mathrm{x}=8.5$ in. and $\mathrm{x}=10.0$ in.

Total pressure surveys were conducted downstream of the nozzle plume and wedge shock interaction, at an axial location of 9.0 in., or 1.5 in. downstream of the nozzle exit. The survey was conducted in the vertical direction from $\mathrm{z}=-1.5$ in. to $\mathrm{z}=1.5 \mathrm{in}$. For the region of total pressure between $\mathrm{z}=-1$ in. to 1 in., the total pressure above the centerline was higher than below the centerline, indicating deflection of the inner nozzle plume in the upward direction (Fig. 12f). The static pressure was also surveyed downstream of the nozzle plume and wedge interaction, at the same location as the total pressure. This vertical profile was also non-symmetric (Fig. 12g) in the region between $\mathrm{z}=-1 \mathrm{in}$. to $1 \mathrm{in}$, , and shows that the nozzle plume was deflected upward by the wedge flow at this location. The deflection is validated by the shadowgraph in the sub-figure of Fig. 12a, displaying a close-up of the inner nozzle plume and wedge interaction; the figure clearly shows how the nozzle plume deflects upward with the wedge angle, and back downward toward the plume centerline.

\section{Conclusions}

Fundamental research for sonic boom reduction is needed to quantify the interaction of shock waves generated from the aircraft wing or tail surfaces with the exhaust plume. Often, aerodynamic tailoring for sonic boom reduction is performed without taking into consideration propulsion system interactions on near-field aft-body pressure waveforms. To better understand the importance of these effects, this study analyzed a small-scale plume and shock wave interaction, comparing experimental measurements with simulations from three CFD flow solvers. General results indicate that plume and shock interactions can have a distinguishable impact on the near-field pressure signature that is propagated to the ground. Better characterization of the effects using more realistic aircraft geometry was also found to be feasible through CFD simulation.

Experimental and computational results demonstrated that commonly used CFD codes, Wind-US and FUN3D could predict the behavior of the coaxial nozzle flow without a wedge shock generator. Results also demonstrated that FUN3D and Cart3D could predict the behavior of the inner nozzle plume and wedge shock interaction.

The Wind-US CFD code, with a structured mesh, demonstrated high fidelity results that resolved many details for the coaxial nozzle flow. The FUN3D unstructured CFD code also demonstrated high fidelity results but did not resolve as many details (such as the wake behind the Mach disk) of the coaxial nozzle flow field due to differences in grid resolution. Even though the thee-dimensional FUN3D grid used 60 times more grid overall, the grid density directly downstream of the nozzle exit plane was less dense than the Wind-US axisymmetric grid. However, the lack of detail in FUN3D did not affect the overall prediction.

Cart3D captured the leading shock from the wedge, but predicted a delayed trailing shock, demonstrating its capability to capture the interaction with slightly less fidelity than the other two codes. Cart3D is often used for sonic boom design and the small differences in results indicate that Cart3D can be used for the screening of design concepts. When Cart3D is used for a design process, a high fidelity analysis using a viscous CFD code would be desirable to analyze a final vehicle design with propulsion effects.

\section{References}

${ }^{1}$ Freund, D., Howe, D., Simmons, F., and Schuester, L., "Quiet Spike Prototype Aerodynamic Characteristics From Flight Test," AIAA 2008-125, Jan. 2005.

2 Graham, D., Dahlin, J., Meredith, K., and Vadnais, J., "Aerodynamic Design of Shaped Sonic Boom Demonstration Aircraft," AIAA 2005-8, Jan. 2005.

${ }^{3}$ Putnam, L. and Capone, F., "Experimental Determination of Equivalent Solid Bodies to Represent Jets Exhausting into a Mach 2.20 External Stream," NASA TN-D-5553, 1969.

${ }^{4}$ Castner, R. S., "Analysis of Plume Effects on Sonic Boom Signature for Isolated Nozzle Configurations," NASA TM-2008-215414 (AIAA-2008-3729), June 2008.

${ }^{5}$ Bui, T., "CFD Analysis of the Nozzle Jet Plume Effects on Sonic Boom Signature," AIAA-2009-1054, Jan. 2009.

${ }^{6}$ Castner, R. S., "Slot Nozzle Effects for Reduced Sonic Boom on a Generic Supersonic Wing Section," AIAA2010-1386, Jan. 2010.

${ }^{7}$ Castner, R. S., "Analysis of Exhaust Plume Effects on Sonic Boom for a 59-Degree Wing Body Model," AIAA2011-917, Jan. 2011. 
${ }^{8}$ Castner, R. S., "Exhaust Plume Effects on Sonic Boom for a Delta Wing and Swept Wing-Body Model," AIAA2012-1033, Jan. 2012.

${ }^{9}$ Castner, R., Elmiligui, A., Cliff, S., "Exhaust Nozzle Plume and Shock Wave Interaction", AIAA-2013-12; 51st AIAA Aerospace Sciences Meeting, Grapevine, TX, Jan 7-10, 2013.

${ }^{10}$ Towne, C. E., "Wind-US Users Guide, Version 2.0," NASA/TM-2009-215804, Oct. 2009.

11 Aftosmis, M. J., Berger, M. J., and Melton, J. E., "Robust and Efficient Cartesian Mesh Generation for Component-Based Geometry,” AIAA Journal, Vol. 36, No. 6, 1998, pp. 952-960.

${ }^{12}$ Aftosmis, M. J., Berger, M. J., and Adomavicius, G., "A Parallel Multilevel Method for Adaptively Refined Cartesian Grids with Embedded Boundaries," AIAA Paper 2000-0808, 38 ${ }^{\text {th }}$ Aerospace Sciences Meeting and Exhibit, Reno, NV, Jan. 2000.

${ }_{13}$ Aftosmis, M. J.; and Berger, M. J., "Multilevel Error Estimation and Adaptive H-Refinement for Cartesian Meshes with Embedded Boundaries," AIAA Paper 2002-0863, 40th AIAA Aerospace Sciences Meeting and Exhibit, Reno, NV., Jan. 2002.

${ }^{14}$ Nemec, M., and Aftosmis, M. J., "Adjoint Error-Estimation and Adaptive Refinement for Embedded-Boundary Cartesian Meshes," AIAA Paper 2007-4187, $18^{\text {th }}$ AIAA CFD Conf., Miami, FL, June 2007.

${ }^{15}$ Nemec, M., Aftosmis, M. J., and Wintzer, M., "Adjoint-Based Adaptive Mesh Refinement for Complex Geometries," AIAA Paper 2008-0725, Jan. 2008.

16 Wintzer, M., Nemec, M., and Aftosmis, M., "Adjoint-Based Adaptive Mesh Refinement for Sonic Boom Prediction," AIAA-2008-6593, Aug. 2008.

${ }^{17}$ Cliff, S. E., Thomas, S. D., McMullen, M. S., Melton, J.E., and Durston, D. A., "Assessment of Unstructured Euler Methods for Sonic Boom Pressure Signatures Using Grid Refinement and Domain Rotation Methods," NASA TM-2008-214568, Sept. 2008.

${ }_{18}$ Aftosmis, Michael, Nemec, Marian, and Cliff, Susan, "Adjoint-Based Low-Boom Design with CART3D (Invited), AIAA-2011-3500, $29^{\text {th }}$ AIAA Applied Aerodynamics Conference, Hawaii, June, 2011.

${ }^{19}$ Elmiligui, Alaa, Cliff, Susan, Aftosmis, Michael, Nemec, Marian, Parlette, Edward, Wilcox, Floyd, and Bangert, Linda, "Sonic Boom Computations for a Mach 1.6 Cruise Low Boom Configuration and Comparisons with Wind Tunnel Data (Invited), AIAA-2011-3496, $29^{\text {th }}$ AIAA Applied Aerodynamics Conference, Hawaii, June, 2011.

${ }^{20}$ Elmiligui, A., Cliff, S., Wilcox, F., and Thomas, S. "Numerical Predictions of Sonic Boom Signatures for Straight Line Segmented Leading Edge Model", Seventh International Conference on Computational Fluid Dynamics, ICCFD7-2004, Big Island, Hawaii, July 9-13, 2012.

${ }^{21}$ Anderson, W. K. and Bonhaus, D. L., "An Implicit Upwind Algorithm for Computing Turbulent Flows on Unstructured Grids," Computers and Fluids, Vol. 23, No. 1, 1994, pp. 1-22.

${ }^{22}$ Anderson, W. K., Rausch, R. D., and Bonhaus, D. L., "Implicit/Multigrid Algorithm for Incompressible Turbulent Flows on Unstructured Grids," AIAA Paper 95-1740, 1995.

${ }^{23}$ Nielsen, E. J., Aerodynamic Design Sensitivities on an Unstructured Mesh Using the Navier-Stokes Equations and a Discrete Adjoint Formulation, Ph.D. thesis, Virginia Polytechnic Institute and State University, 1998.

${ }^{24}$ Venkatakrishnan, V., "Convergence to Steady State Solutions of the Euler Equations on Unstructured Grids with Limiters," Journal of Computational Physics, Vol. 118, No. 1, 1995, pp. 120-130.

${ }^{25}$ Diskin, B., Thomas, J. L., Nielsen, E. J., Nishikawa, H., and White, J. A., "Comparison of Node-Centered and Cell- Centered Unstructured Finite-Volume Discretizations: Viscous Fluxes," AIAA Journal, Vol. 48, No. 7, July 2010, pp. 1326-1338.

${ }^{26}$ Roe, P. L., "Approximate Riemann Solvers, Parameter Vectors, and Difference Schemes," Journal of Computational Physics, Vol. 43, 1981, pp. 357-372.

${ }^{27}$ Nielsen, E. J., Lu, J., Park, M. A., and Darmofal, D. L., “An Implicit, Exact Dual Adjoint Solution Method for Turbulent Flows on Unstructured Grids," Computers and Fluids, Vol. 33, No. 9, 2004, pp. 1131-1155.

${ }^{28}$ Spalart, P. R. and Allmaras, S. R., "A One-Equation Turbulence Model for Aerodynamic Flows," La Recherche Aerospatiale, Vol. 1, No. 1, 1994, pp. 5-21.

${ }^{29}$ Pinckney, S. Z.: A Short Static Pressure Probe Design for Supersonic Flow, NASA TN D-7978. 


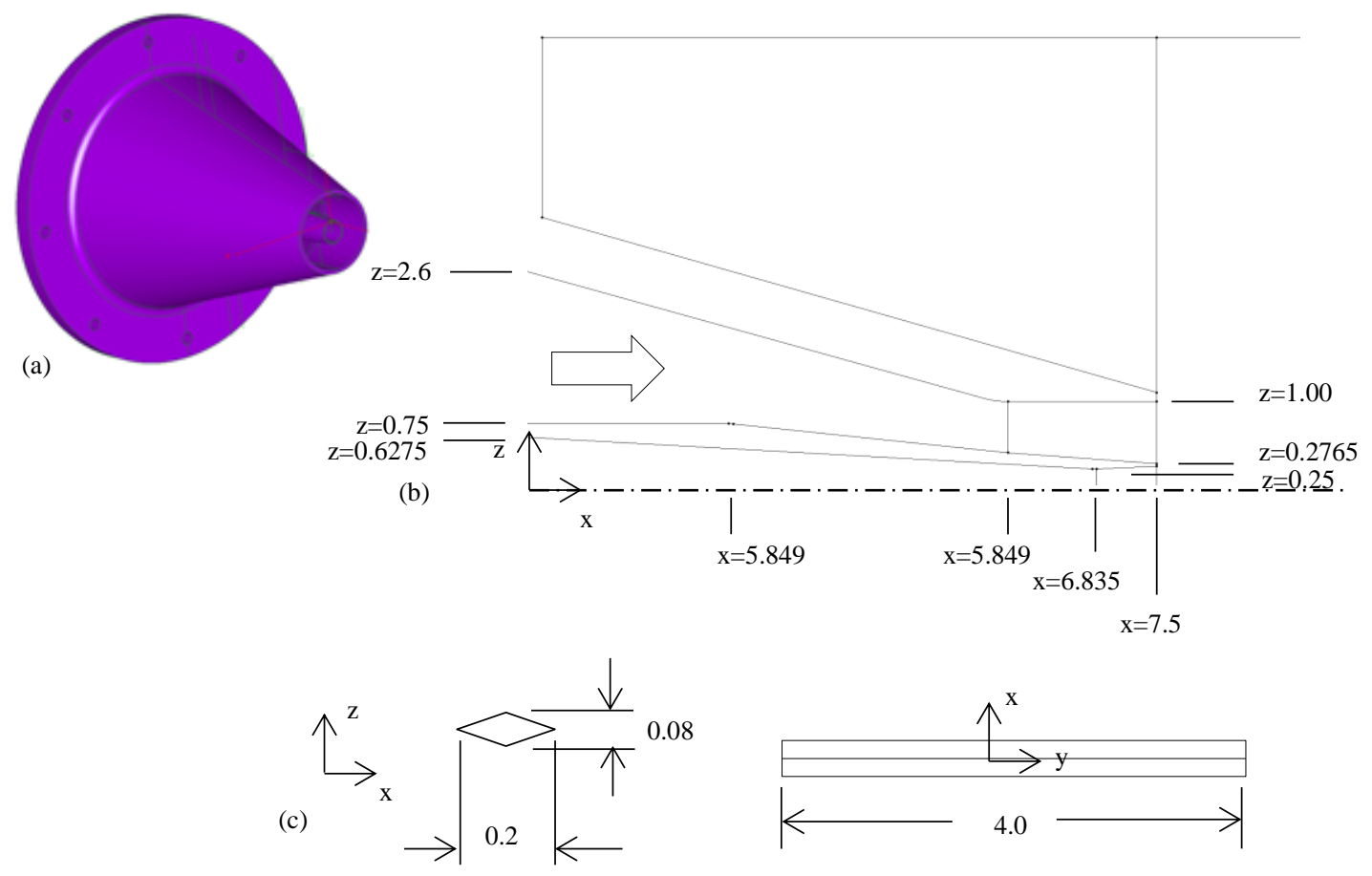

Fig. 1. Co-axial nozzle (a) assembly, (b) nozzle dimensions and (c) wedge dimensions.

(a)
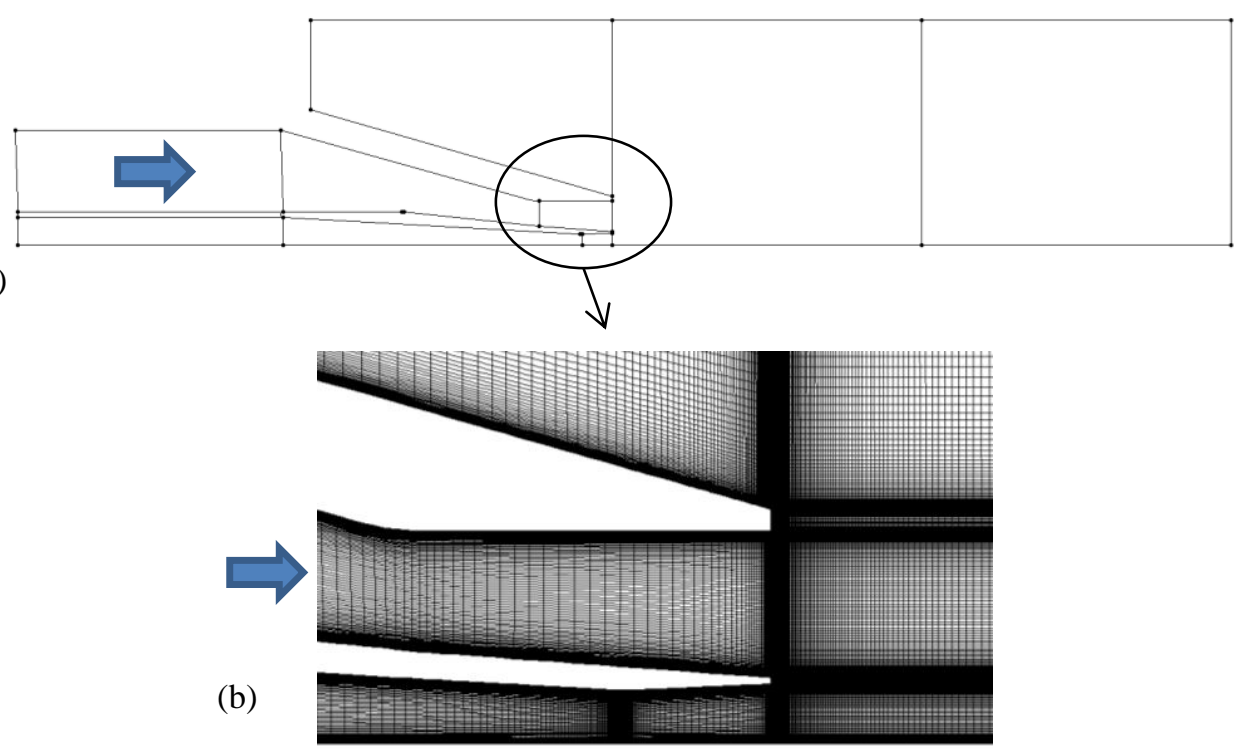

Fig. 2. Axisymmetric Wind-US CFD (a) computational domain and (b) nozzle mesh. 
Table 1. CFD Flow Conditions

\begin{tabular}{lccc}
\hline \multicolumn{2}{c}{ Nozzle Stream } & \multicolumn{2}{c}{ Free-jet stream } \\
$\mathrm{T}_{\mathrm{o}}{ }^{\circ} \mathrm{R}$ & 530 & $\mathrm{~T}_{\infty}{ }^{\circ} \mathrm{R}$ & 530 \\
$\mathrm{NPR}$ & 4.47 & $\mathrm{P}_{\infty}$ & 14.4 \\
& & $\mathrm{M}_{\infty}$ & 1.6 \\
\hline
\end{tabular}

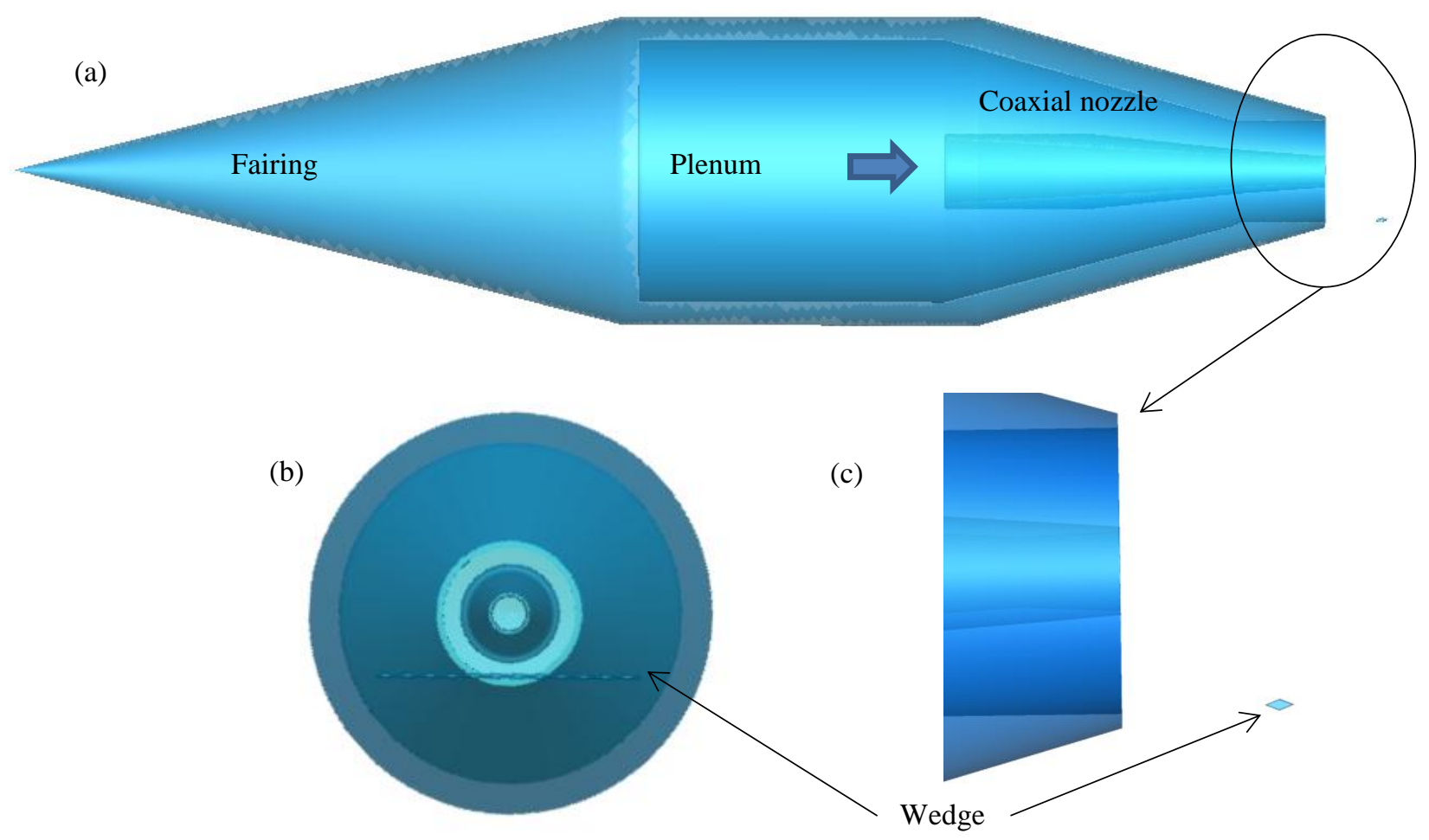

Fig. 3. Surface geometry for Cart3D: (a) side view, (b) end view. 


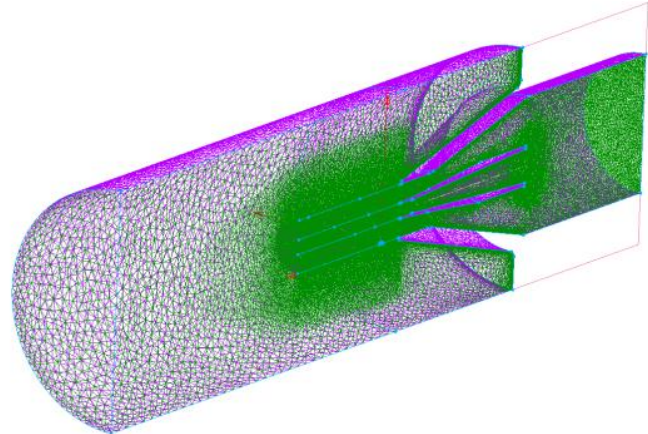

(a) Isometric
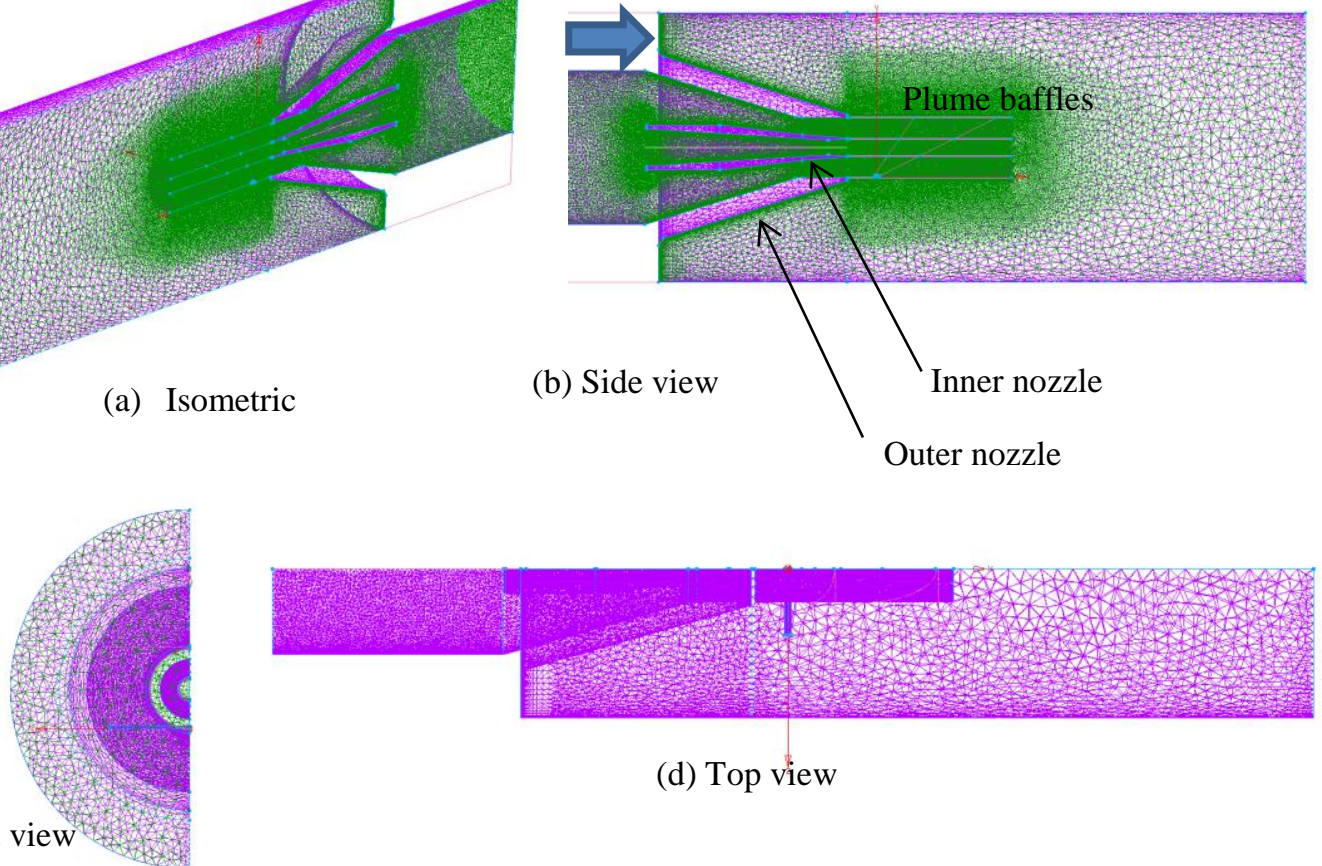

(d) Top view

(c) End view
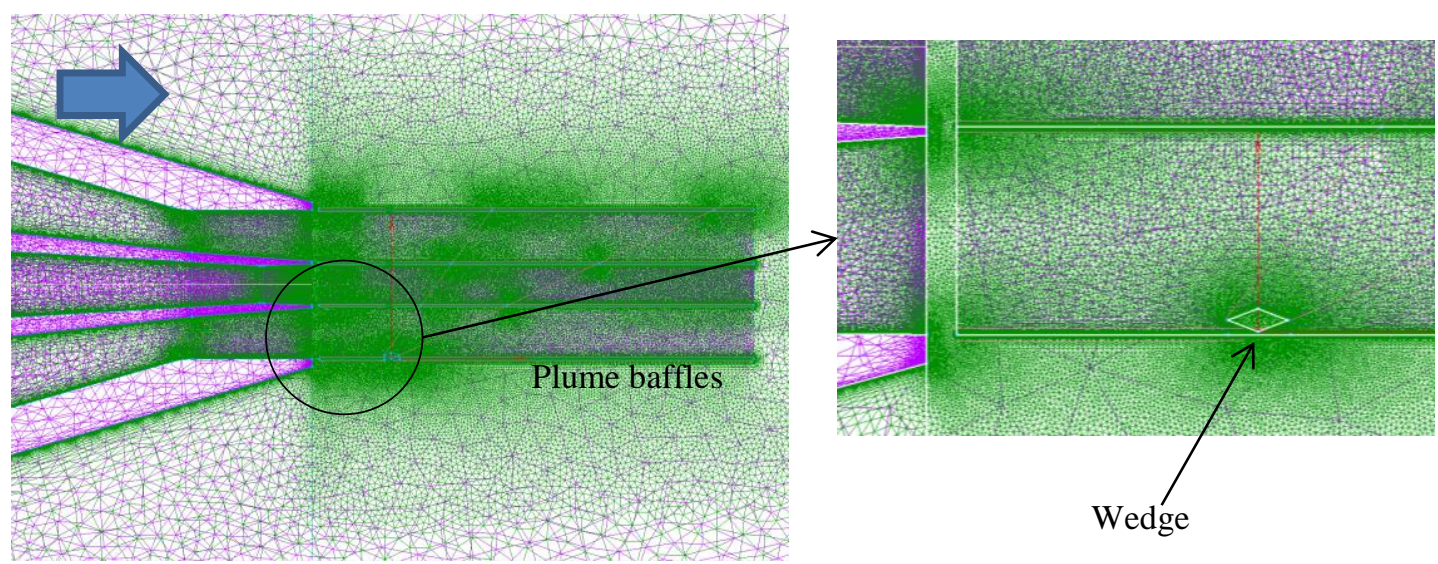

(e) Close view

Fig. 4. Three dimensional CFD domain with wedge. 


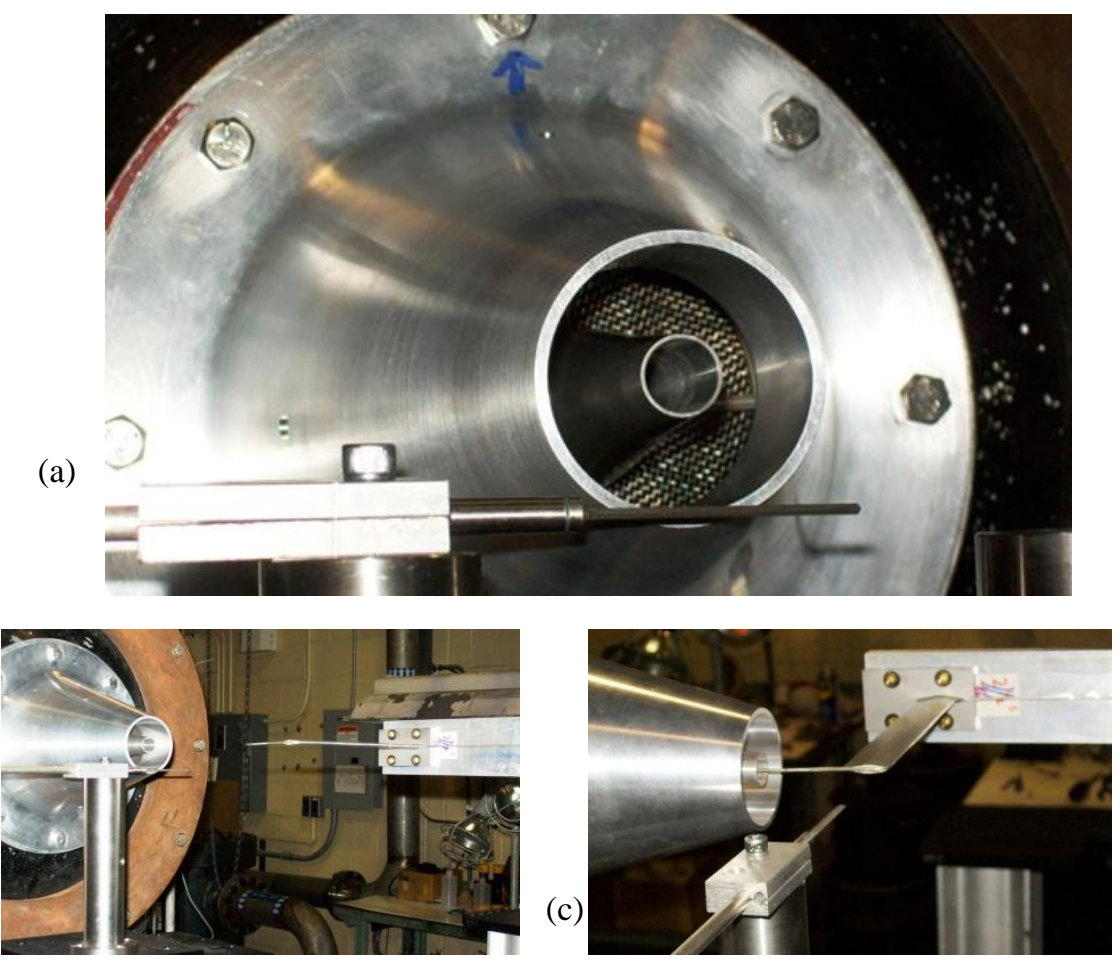

Fig. 5. Experimental setup, coaxial nozzle with wedge: (a) nozzle and wedge location, (b) wedge support and probe support, (c) probe located at nozzle exit. 

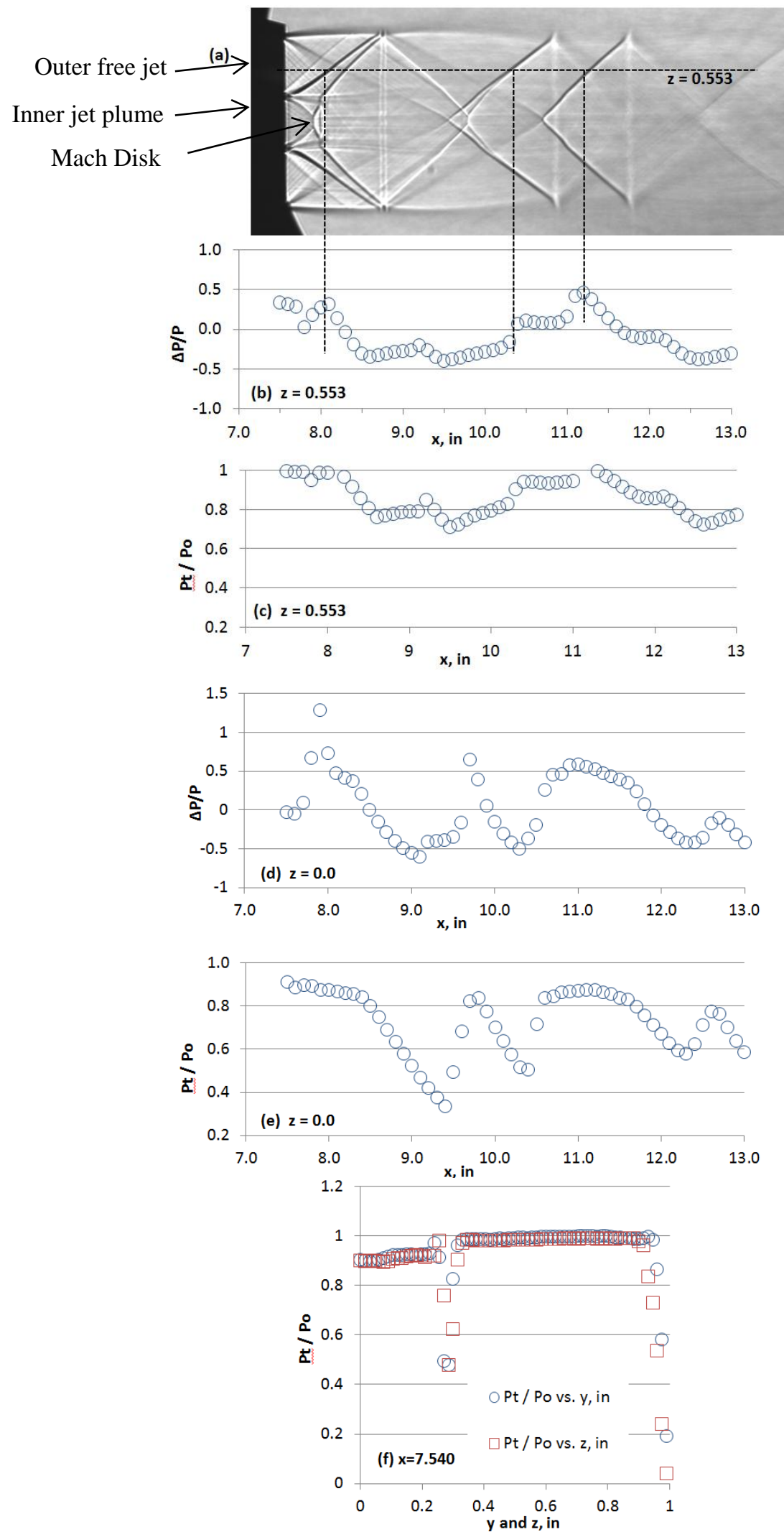

Fig. 6. Experimental Results with no wedge. 

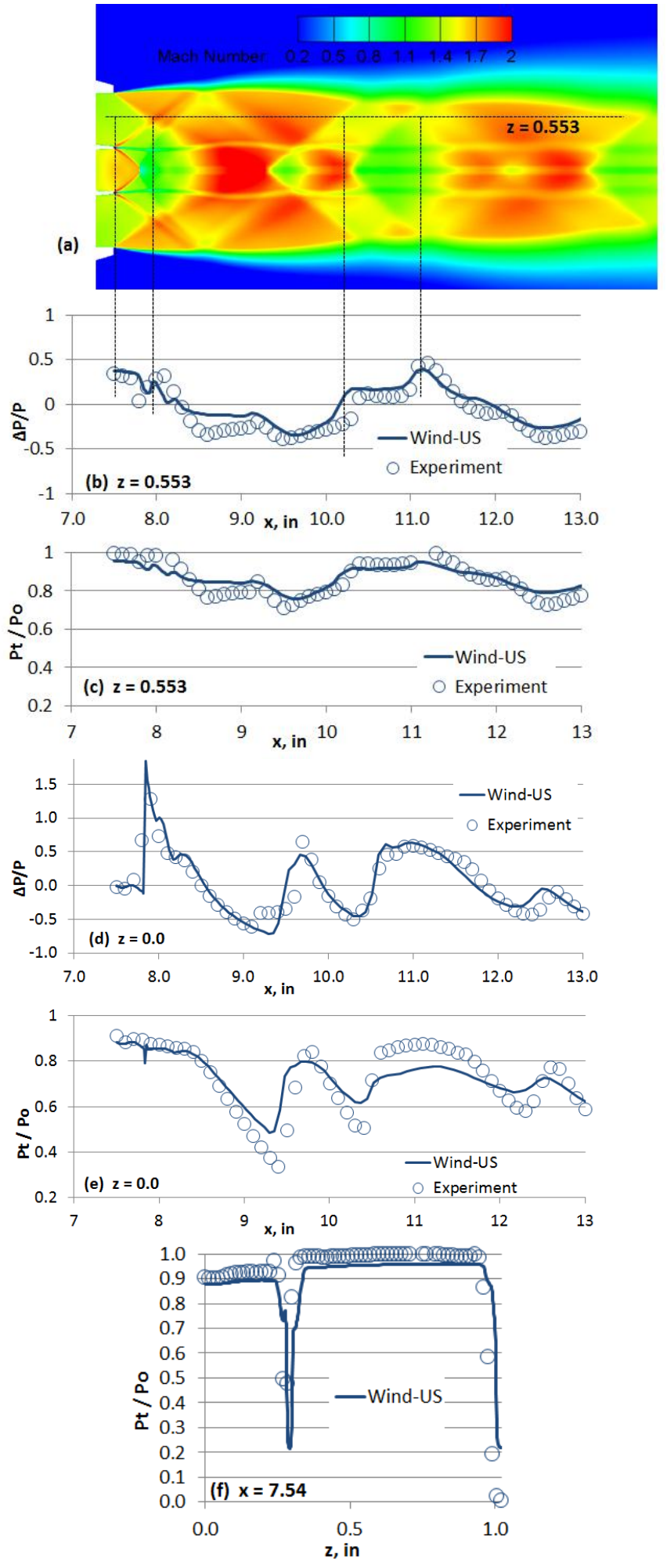

Fig. 7. Wind-US CFD solution with no wedge. 

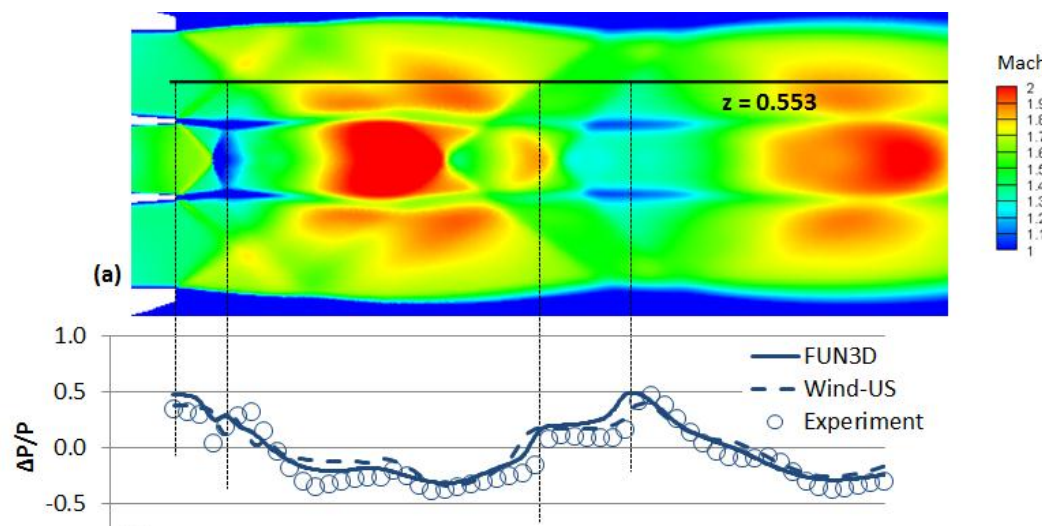

(b) $z=0.553$

$-1.0$
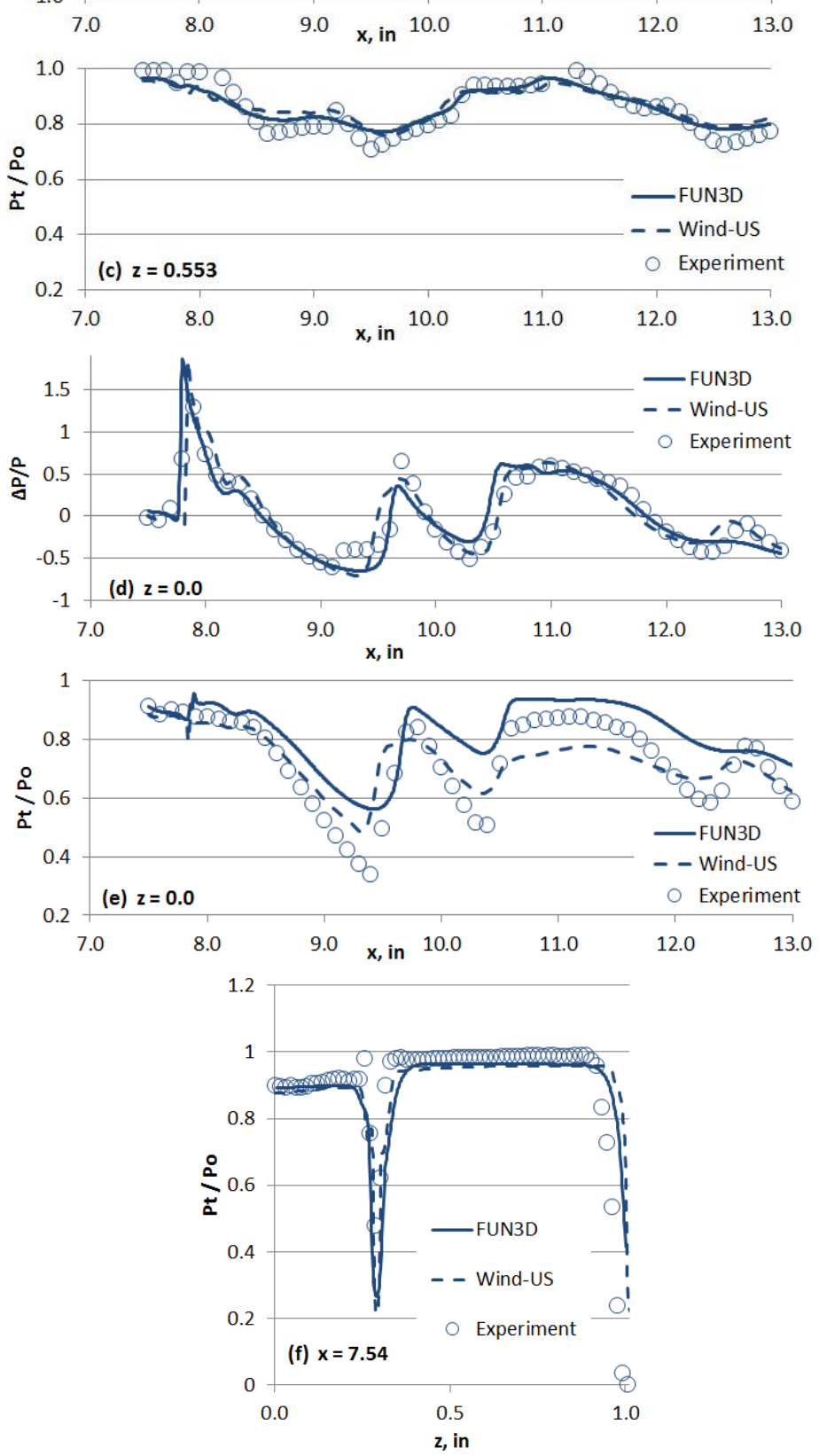

Fig. 8. FUN3D CFD solution with no wedge.

American Institute of Aeronautics and Astronautics 


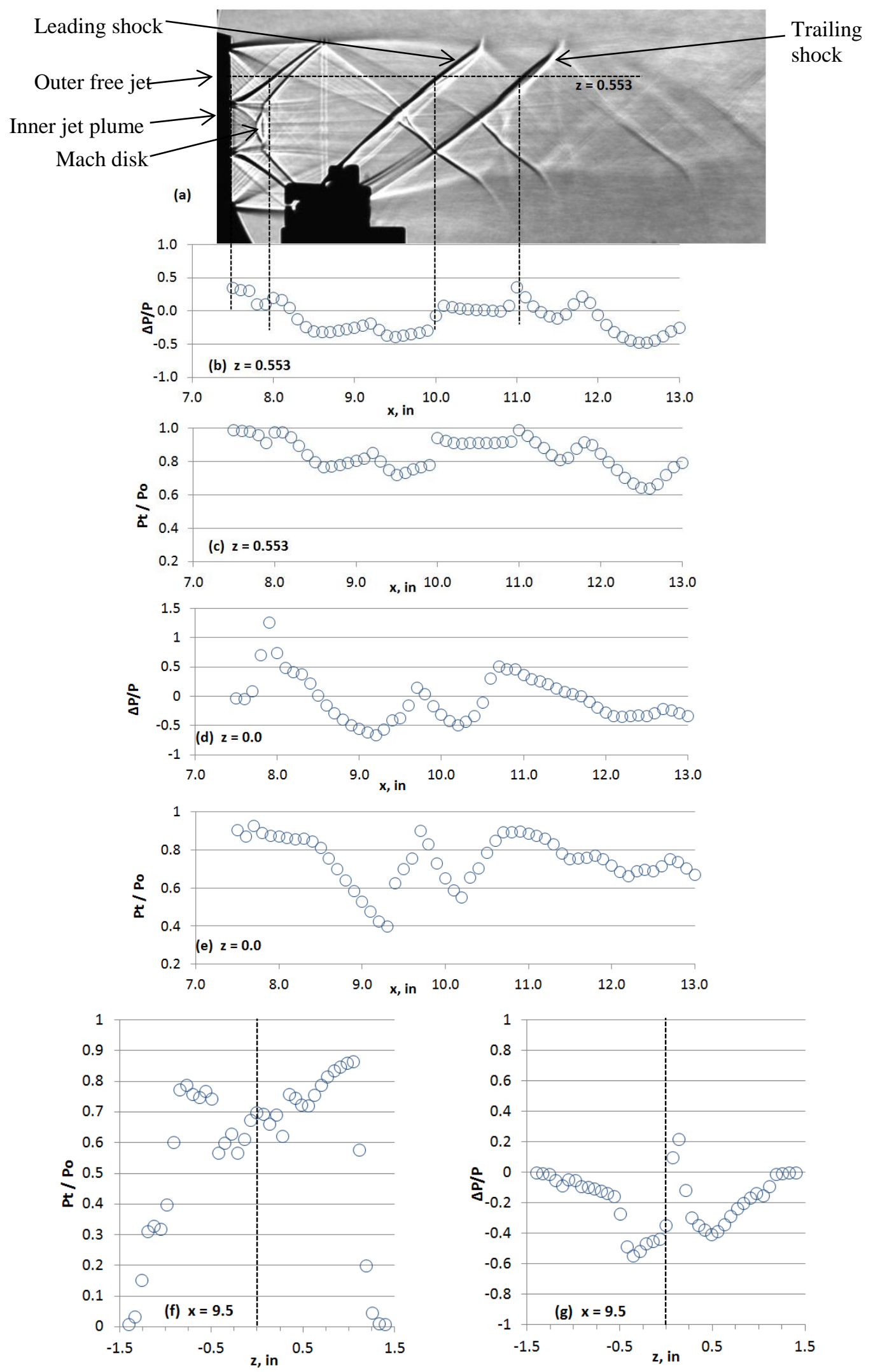

Fig. 9. Experimental Data with wedge at $x=8.5$ in. and $z=-0.95$ in.

American Institute of Aeronautics and Astronautics 

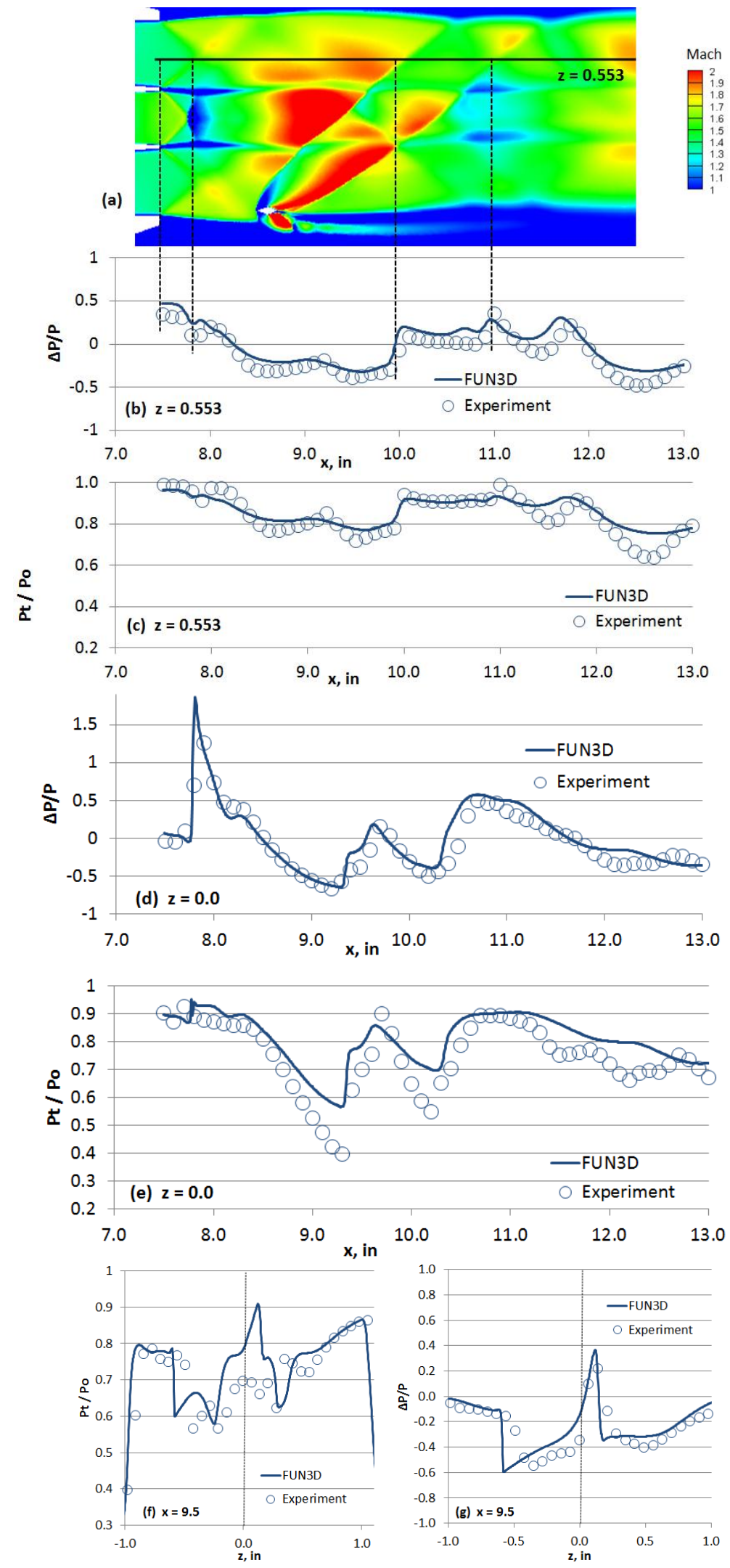

Fig. 10. FUN3D CFD solution with wedge at $x=8.5$ in. and $z=-0.95$ in. 


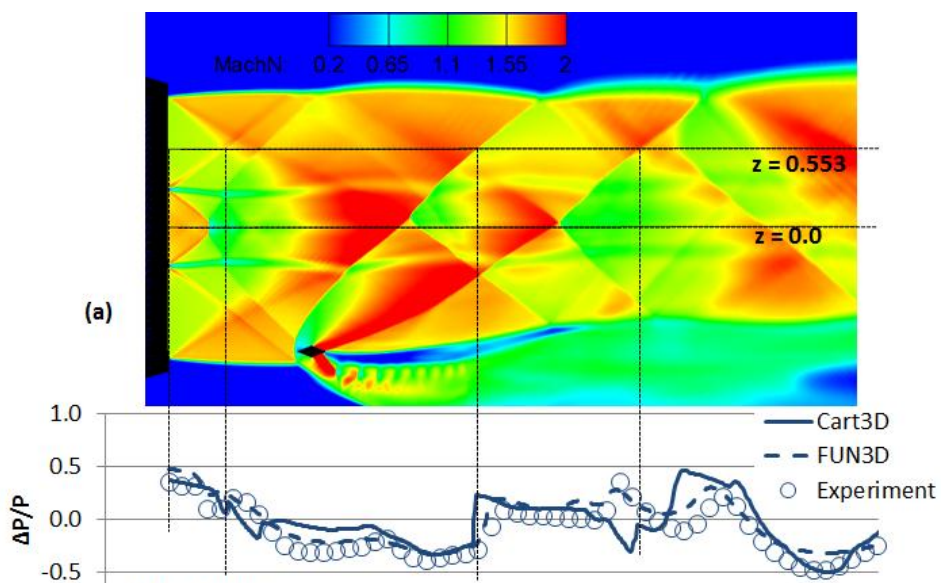

(b) $z=0.553$
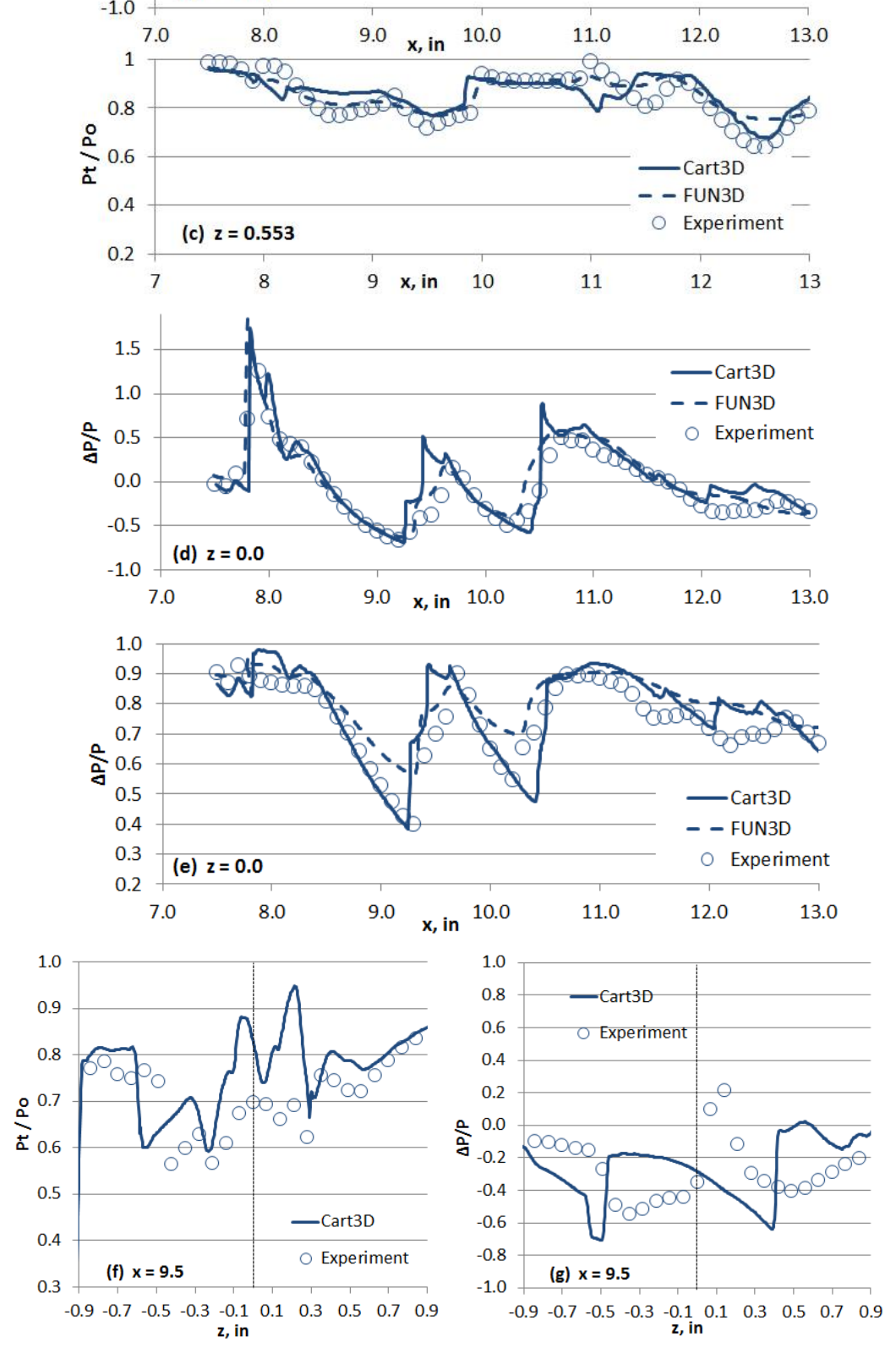

Fig. 11. Cart3D CFD solution with wedge at $x=8.5$ in. and $z=-0.95$ in.

American Institute of Aeronautics and Astronautics 

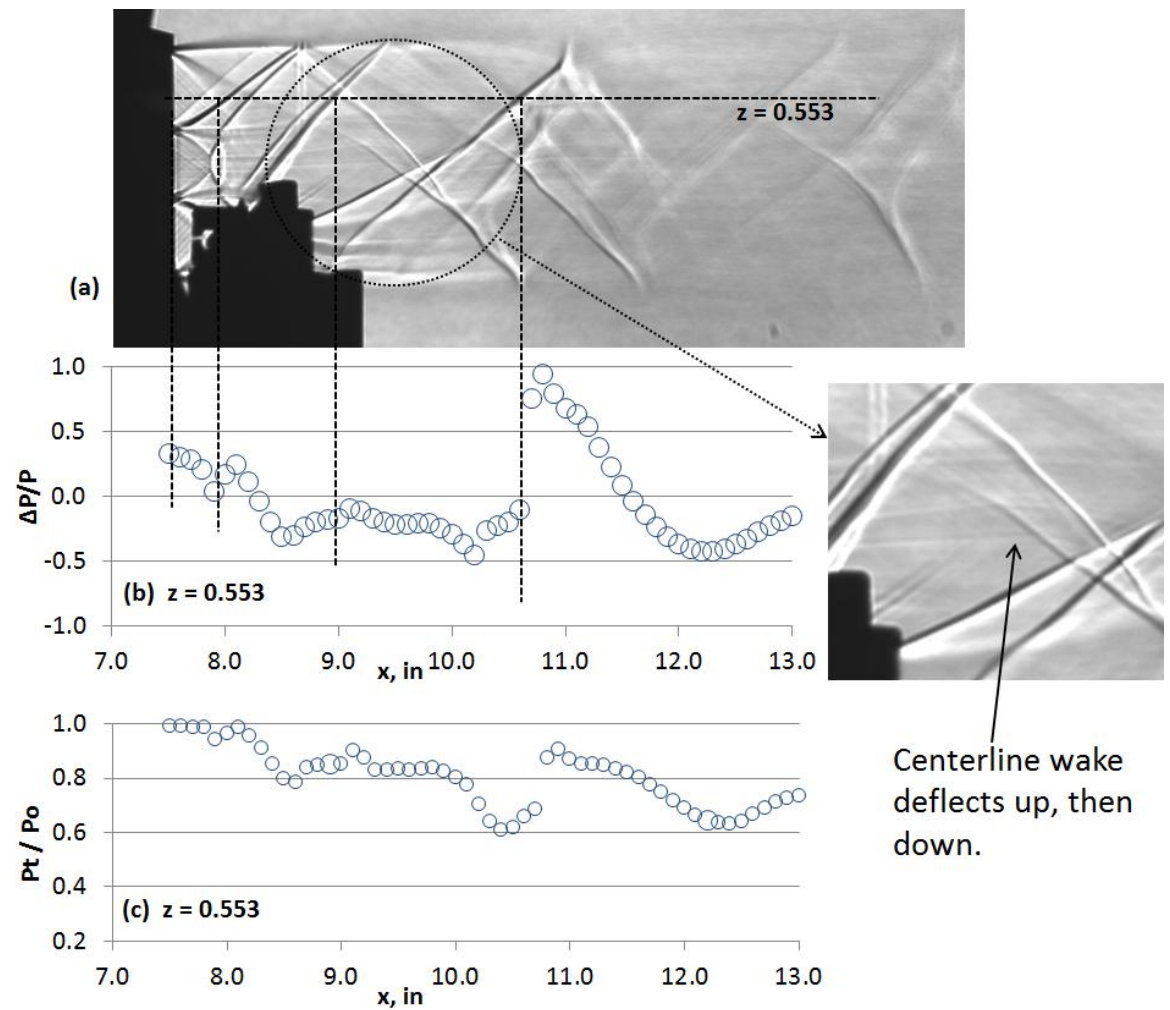

Centerline wake deflects up, then down.
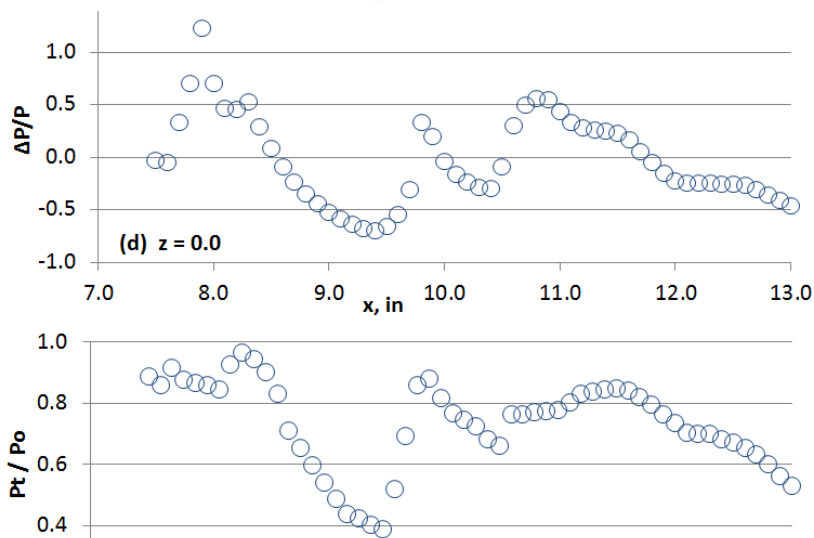

0.4

0.2

(e) $\mathrm{z}=0.0$

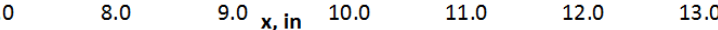
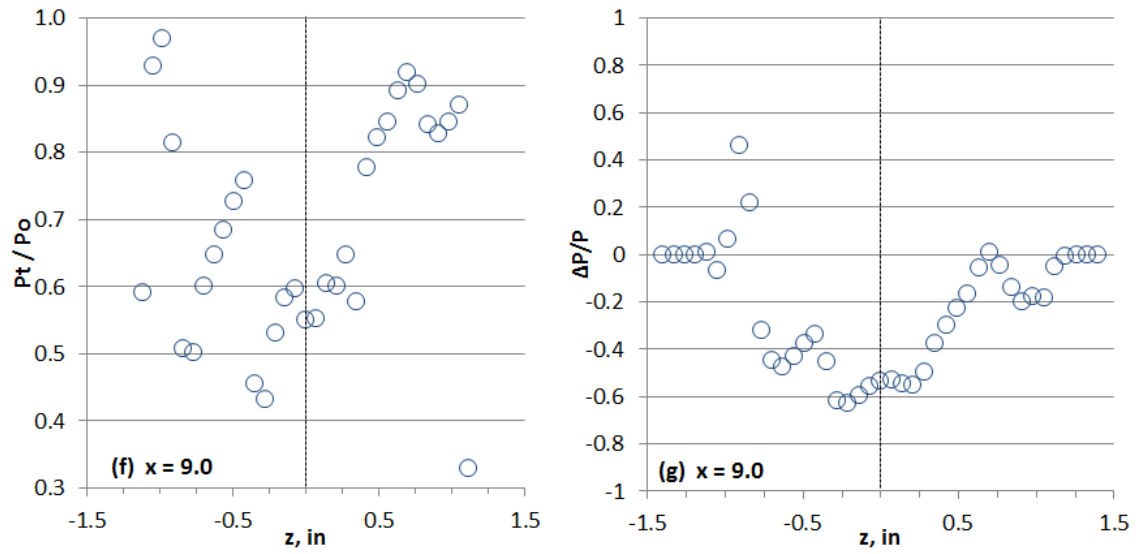

Fig. 12. Experimental data with wedge at $x=8.0$ in. and $z=-0.61$ in.

American Institute of Aeronautics and Astronautics 